\title{
Acculturation and Life Satisfaction Among Immigrant Mexican Adults
}

\author{
Flavio F. Marsiglia \\ Jaime M. Booth \\ Adrienne Baldwin \\ Stephanie Ayers
}

\begin{abstract}
The numbers of Mexican Americans living in the United States, many of whom are first generation immigrants, are increasing. The process of immigration and acculturation can be accompanied by stress, as an individual attempts to reconcile two potentially competing sets of norms and values and to navigate a new social terrain. However, the outcomes of studies investigating the relationship between levels of acculturation and well-being are mixed. To further investigate the dynamic of acculturation, this article will address the impact of acculturation and familismo, on reported life satisfaction and resilience among Mexican American adults living in the Southwest $(N=307)$, the majority (89\%) of which are immigrants. The findings indicate that bilingual individuals report significantly higher levels of life satisfaction and resilience than their Spanish-speaking counterparts do. Speaking primarily English only predicted higher levels of resilience but not life satisfaction. Implications for social work practice with Mexican American immigrants are discussed.
\end{abstract}

Keywords: Acculturation, Mexican-American, life satisfaction, resilience

Latinos now make up a large majority of the minority groups in the United States and their numbers are growing, with Mexican Americans representing 10\% of the total population in the United States (U. S. Census Bureau, 2012). While the U. S. population increased by only $9 \%$ between 2000 and 2009, the Latino population experienced a $37 \%$ increase (Saenz, 2010). This growing number of Latinos, specifically Mexican Americans, presents an opportunity for advancing our knowledge about the distinct challenges that migration and acculturation may have on the mental health of Latinos, and accordingly, what policy and service delivery changes are needed to address those needs (Castro, Marsiglia, Kulis, \& Kellison, 2010; Lara, Gamboa, Kahramanian, Morales, \& Hayes Bautista, 2005).

When cultures interact because of migration, individuals are forced to negotiate their identity and reconcile their culture of origin with the dominant culture in the receiving country (Redfield, Linton, \& Herskovits, 1936). The process of acculturation can cause conflict within individuals and families because they feel the competing pressures of adopting new cultural norms and maintaining the ways of life of their country of origin (Nguyen \& Peterson, 1993). Extensive research has been done examining the relationship between acculturation and poor mental health; however, findings are mixed and very few

\footnotetext{
Flavio F. Marsiglia, Ph. D., MSW, is the Distinguished Foundation Professor of Cultural Diversity and Health and Director of the Southwest Interdisciplinary Research Center [SIRC]; Jaime M. Booth MSW, is a Graduate Research Associate at SIRC; Adrienne Baldwin, MSW, is a Graduate Research Associate at SIRC; Stephanie Ayers, Ph. D., is the Associate Director of Research at SIRC. This research is supported by funding from the National Institutes of Health/National Institute on Minority Health and Health Disparities (NIMHD/NIH), award P20 MD002316-05 (F. Marsiglia, P.I.). The project is housed in the School of Social Work, College of Public Programs, at Arizona State University in Phoenix.
} 
studies include measures of well-being or positive mental health (Konerua, Weisman de Mamania, Betancourt, \& Flynn, 2007). Understanding the impact of a culture of origin and host culture on well-being enables social workers to promote positive mental health in both micro and macro practice settings. To that end, this article addresses the impact of acculturation and familismo, a traditional Mexican cultural norm, on reported general life satisfaction and resilience among a sample of recent Mexican immigrants living in the southwestern United States.

\section{Life Satisfaction}

Healthy People 2020 identified life satisfaction, defined as a distinct construct representing a cognitive and global evaluation of the quality of one's life, as an indicator of well-being (Pavot \& Diener, 2008; U. S. Department of Health and Human Services, 2012). The construct of life satisfaction addresses an individual's ability to 1) have a life that meets their needs (Karan, Lambour, \& Greenspan, 1990), and 2) be "happy" (Andrews \& McKennell, 1980). Life satisfaction is associated with stable marriages, selfefficacy, goal orientation, work ethic, and positive intra- and interpersonal outcomes (Diener, Napa-Scollon, Oishi, Dzokoto, \& Suh., 2000; Gilman, Huebner, \& Laughlin, 2000; Myers \& Diener, 1995). Although life satisfaction is a distinct dimension of mental health, it strongly and negatively correlates with depression (Headey, Kelley, \& Wearing, 1993). Life satisfaction is a psychological strength that has a buffering effect against stressful life events (Suldo \& Huebner, 2004). This buffering effect points to the potential of life satisfaction as a viable outcome in its own right, but also a protective factor against the development of more serious mental health challenges.

\section{Resilience}

In addition to life satisfaction, resilience is a key component of the positive psychology movement, which claims that the best way to address mental health issues is to promote strengths that may act as buffers against pathology (Suldo \& Hueber, 2004; Greene, Galambos, \& Lee, 2004). Resilience is the ability to bounce back in the face of stressful life events (Tugade \& Fredrickson, 2004). Resilient children and adolescents develop abilities to respond with resourcefulness and tenacity when confronted with unwanted challenges (Fraser, Richman, \& Galinsky, 1999). A resilient individual has a strong commitment to self, is willing to take action to deal with problems, has a positive attitude toward his or her environment, has a strong sense of purpose, and has developed a strong internal locus of control that enables him or her to view obstacles as challenges that can be overcome (Hérbert, 1996).

Both risk and resilience are discussed within the ecological systems framework. Fraser et al. (1999) has advanced a model of resilience that includes interactions between all levels of the ecological system: micro, mezzo, and macro. In this framework, resilience is a dynamic response to a multiplex of biological, psychological, social, and other environmental risks (Fraser et al., 1999; Jenson \& Fraser, 2006). Resilience is expressed through an individual's ability to adapt to risks that occur on all levels of the system by leveraging resources that may be present in different arenas (Jenson \& Fraser, 
2006). For all people and for Latinos in particular, a cohesive and supportive family environment plays an important role in the development of resilience (Hérbert, 1996).

Resilience acts as a buffer for negative mental health outcomes in three ways: 1) minimizing harm, 2) protection, and 3) promotion (Davydov, Stewart, Ritchie, \& Chaudieu, 2010). Resilience not only enables individuals to recover more quickly when they encounter stressful situations (e.g., minimizing harm), but can also have a protective effect, enabling individuals who have experienced adversity as children to have better relationships in adulthood (Collishaw et al., 2007). Resilience decreases the number of events experienced as stressful, therefore increasing overall well-being (Ong, Bergeman, Bisconti, \& Wallace, 2006).

Based on the ecological model, researchers are now beginning to view resilience as the result of the interactive process between risk, protection, and promotion (Jenson \& Fraser, 2006). The transition from a focus on deficits and defects to protective factors represents a move toward a strengths-based approach to problem solving (Guo \& Tsui, 2010; Masten, 2001). Although resilience is an individual response, it is conditional on both individual and environmental factors (Fraser et al., 1999). The ecological model provides the most thorough representation of resilience because it considers the influence of context, including neighborhood, school, peers, and family influences on resilience.

\section{Acculturation and Mental Health}

Acculturation is broadly defined as the process of adaptation that results when two cultural groups interact, and/or the extent to which an individual assumes the norms and values of the host culture (Lueck, \& Wilson, 2011; Miranda, Estrada \& Firpo-Jimenez, 2000). Acculturation is a vitally important process to consider when discussing both life satisfaction and resilience among Latinos in the United States. Historically, it has been hypothesized that the process of acculturation is stressful and may negatively impact mental health because it forces an individual to negotiate two potentially conflicting identities (Stonequist, 1935) and integrate into a society that can be hostile to minorities (U. S. Department of Health and Human Services, 2001). The more an individual's beliefs about their cultural group are clearly and confidently defined, the more likely they are to have clear and confident definitions of the personal self and self-esteem markers of psychological well-being (Usborne, 2010). Living between cultures may be more stressful than total assimilation or no acculturation at all. However, an individual's level of cognitive flexibility, which enables them to switch their cultural orientation depending on the context, is more protective against negative mental health outcomes than high levels of acculturation or assimilation (Lechuga, 2008).

The complexity of the relationship between acculturation or assimilation and mental health is seen in the disparate results of scientific studies, with some findings suggesting that high levels of acculturation are associated with a decrease in negative mental health outcomes, while others have shown the opposite (Abrams, Allen, \& Gray, 1993; Miranda \& Umhoefer, 1998; Shen \& Takeuchi, 2001). In a study comparing the mental health of recent Mexican American immigrants and Mexican Americans who were born either in the United States or who had lived in the United States for more than 13 years, recent 
immigrants were found to have more positive outcomes (U. S. Department of Health and Human Services, 2001). However, this study did not include measures of acculturation. Ortiz and Arce (1984) interviewed 1,300 Mexican families about their mental health and found that the less acculturated individuals reported higher levels of life satisfaction. Similarly, in another study of both immigrant and native-born older Mexican Americans, a positive relationship was found between depression and acculturation; however, acculturation did not significantly predict life satisfaction (Cuellar, Bastida, \& Braccio, 2004).

Conversely, in two studies, low levels of acculturation among Mexican American women were associated with higher levels of depressive symptomatology (Salgado de Snyder, 1987) and feelings of hopelessness (Melville, 1978). Recently, Torres (2010) found that a variety of factors associated with being an immigrant in the United States increased the likelihood of reporting depression. These mixed findings suggest that both high levels of acculturation and low levels of acculturation do not necessarily mitigate distress among Mexican Americans and further leads us to question if multiculturalism, or retaining aspects of one's culture of origin while adapting norms and values of the host culture, may positively influence resilience and life satisfaction.

\section{Familism}

Although studies have traditionally treated acculturation as a single item, underlying cultural norms may also be possible risk or protective factors (Rodriguez, Mira, Paez, \& Myers, 2007). For instance, having a bicultural orientation is more protective when individuals are grounded in social networks within both cultures (LaFramboise, Coleman, \& Gerton, 1993). Familism, a traditional Latino norm, may provide a more complex picture of acculturation and account for one aspect of Latinos' culture of origin that promotes "groundedness" and positive mental health. The idea of familism refers to cultural norms of loyalty, solidarity, and reciprocity with both the nuclear and extended family (Martín \& Martín, 1991). Among Latinos, values and norms like familism are taught in the family and serve as a source of resilience, giving youth the context in which to practice adaptive behaviors (Masten, 2001). The social support and sense of belonging that result from being part of a close family are protective factors against negative mental health outcomes (Castillo, Conoley, \& Brossart, 2004). In a study with second-generation Mexican American youth, adherence to traditional norms and values seemed to influence the youth's identity, supporting resilience in the face of stress (Holleran \& Waller, 2003). Similar findings were reported in a quantitative study that found that maintaining ties to the traditional Latino culture was protective against distress (Torres, 2010).

\section{Multicultural Model}

While classic studies characterized acculturation as a unidirectional linear process in which an individual adapts to norms of the dominant culture (Gordon, 1964), recently, scholars have recognized the processes' bidirectional nature, in which individuals are able to retain aspects of their culture of origin while adapting aspects of the host culture (Berry, 2005). This model recognizes that individuals can simultaneously maintain the identity, norms, and values of their culture of origin while also learning successfully to 
interact with the host culture (LaFromboise, Coleman, \& Gerton, 1993). This model further demonstrates that these individuals can maintain separate identities in private and public spaces without causing psychological tension, which may serve as a protective factor (Kelly, 1971). The multicultural model more accurately reflects the dynamic nature of culture and the potential protective effect of maintaining aspects of an individual's culture of origin when compared to models of assimilation; therefore, the multicultural model was used to guide the hypotheses being tested in this research.

Berry (1997) elaborates on this multicultural conception of acculturation by outlining four different reactions to the interactions of culture; 1) integrative, in which individuals maintain norms, beliefs, or customs from their culture of origin, while also incorporating aspects of the host culture; 2) assimilation, in which individuals lose their culture of origin and are completely integrated into the host culture; 3) separation, in which an individual completely rejects the host culture maintaining their culture of origin's attitude, norms, and beliefs; and 4) marginalization, in which an individual is rejected or is rejecting both their culture of origin and the host culture. In a study examining the impact of these four reactions on psychological well-being, integration was associated with positive outcomes while marginalization was associated with negative outcomes (Berry, 2005).

Because the findings on the effects of high levels of acculturation or assimilation on mental health are mixed, and few studies have examined how the process impacts positive aspects of mental health, this study will examine the impact of linguistic acculturation and the endorsement of traditional Latino values, specifically familismo, on life satisfaction and resilience. Based on the multicultural model, it was hypothesized that:

1) Among Latinos, an integrative or multicultural orientation will be associated more with increased life satisfaction and resilience than both assimilated and separated individuals.

2) Latinos with higher levels of familism will have increased levels of life satisfaction and resilience.

\section{Methods}

\section{Sample}

The data in this study came from a four-year-long randomized control trial that tested Families Preparing the New Generation ( $F P N G$ ), a parenting intervention developed to accompany Keepin' it REAL. Taught in school classrooms by teachers, Keepin' it REAL is a culturally-based, evidence-based substance use prevention program for youth designed to: (a) increase drug resistance skills; (b) promote anti-substance use norms and attitudes; and (c) develop effective decision making and communication skills for resisting drugs and alcohol (Marsiglia \& Hecht, 2005). Keepin' it REAL is now recognized as a National Model Program by the Substance Abuse and Mental Health Services Administration (SAMHSA) (Schinke, Brounstein, \& Gardner, 2002). 
All independent variables were measured in the pre-test needs assessment at wave one; while dependent variables, life satisfaction and resilience, were measured at wave three, one year after the treatment group completed the program. Wave three data was utilized because the main variables of interest, life satisfaction and resilience, were not measured at wave two. Pre-test questionnaires were administered in two cohorts: cohort 1 , surveyed in the fall of 2009, and cohort 2 completed the survey in the fall of 2010. All surveys read at a $5^{\text {th }}$ grade level, were available in English or Spanish, and were translated following the procedures described by Rogler (1989). In order to engage parents in the study, parental consents explaining the study and asking parents if they wished to participate were sent home with the students. All children in the 7th grade and parents that agreed to participate in FPNG were included in the sample. Parents could choose one of three options: 1) to consent both parent and youth; 2) to consent youth only; 3) to consent neither parent nor youth. Parental consents were provided in both English and Spanish. Although data was collected from all youth, regardless of their parent's decision to participate in the study, only parent data was used in this analysis due to our focus on the well-being of adults.

Parents who expressed an interest in participating in the study attended a meeting at the school to complete a packet of questionnaires. Trained research staff followed detailed administration instructions that emphasized the confidentiality of responses. Questionnaires were administered in small groups and took from 60-90 minutes to complete. Surveys were completed in the language of preference of the participant with $93 \%$ of parents choosing to complete the questionnaires in Spanish.

In the study, 1,131 seventh-grade students in nine schools (regardless of their race or ethnicity) and their parents were invited to participate in the study; 681 parents completed and returned consents (consent rate of 79\%), 468 parents completed surveys at wave one, and 369 of those returned to complete the survey at wave three. Participants were included in the analysis if they identified as Mexican, Mexican American, Chicano, or another Hispanic or Latino group and who completed a survey at wave three, resulting in a total sample size of 307 . The majority $(89 \%)$ reported being born in a country other than the United States. The sample had a mean age of 38.67, a mean education of more than six years of school, but no high school diploma, $60.91 \%$ of the sample was married, and $86 \%$ was female (See Table 1).

\section{Measurement}

General life satisfaction was measured at wave one and wave three using 10-items in which respondents answered questions about their level of satisfaction with a variety of aspects, ranging from spiritual life to trust in important persons. Possible responses ranged from (1) Not at all, to (5) Extremely (for scale items see Table 2). Because these items appeared to be disparate, a factor analysis was conducted using a PAF rotation. When the analysis was conducted, one factor emerged with an Eigenvalue of 6.47. All items of the scale were retained with factor loadings well above the minimum cut point of .40 (see Table 2). A scale was constructed by summing all items with a final range of possible scores from 10 to 50 and having an $\alpha=.93$. 
Resilience. Although resilience has been operationalized traditionally as the characteristics of an individual that moderates the relationship between stressors and negative outcomes, resilience is ultimately an individual's ability to "successfully cope with changes or misfortune" (Ahern, Kiehl, Lou Sole, \& Byers, 2006, p. 104). The ability to "bounce back" is a quality inherent in the definition of resilience. This conceptualization of resilience was drawn from Tugade and Fredrickson's (2004) definition, which includes an individual's perceived ability to overcome various challenges including anxiety and disappointments. Based on this definition, the three items in the life satisfaction scale that asked the respondents about their ability to overcome challenging life circumstances or emotions were isolated and analyzed in order to examine an individual's level of resilience. A factor analysis was conducted using a PAF rotation and a new item was created. When the exploratory factor analysis was conducted, one factor was retained with an Eiganvalue of 2.40 and factor loadings ranging from .87 to .91 (see Table 1). Given the results of the factor analysis, a new variable, resilience, was created by summing the three items, with responses ranging from 3 to 15 with an $\alpha=.87$.

Acculturation. Despite the conceptual limitations, linguistic-based measures have been useful in identifying English language proficiency as a predictive factor for low acculturative stress, especially for Latino immigrants (Lueck \& Wilson, 2011). Language is a significant aspect of acculturation because language fluency is pertinent in crosscultural communication. Previous research has indicated that language usage (measured by asking participants, "In your home, do you speak...?" and "With your friends, do you speak...?"), explains the variance in levels of acculturation and is therefore an acceptable brief measure (Unger, Ritt-Olson, Wagner, Baezconde-Garbanati, \& Soto, 2007). Acculturation was measured using a 3-item scale $(\alpha=.90)$ and by asking participants, "Today, 1) you speak, 2) you read, and 3) the language of the television and radio shows you watch or listen to are:" with the following possible responses (1) only in a language other than English, such as Spanish, (2) another language more than English, (3) both languages equally, (4) English more than other languages, and (5) only English. To create the scale, these items were summed, resulting in a range of scores from 3 to 15 . Cut off points were then created, with less than six indicating a primarily Spanish-speaking individual (e. g. low acculturation), between seven and nine was considered bilingual (e. g. bicultural), and 10 or greater indicating a primarily English speaking individual (e. g. high acculturation).

Familism, an 8-item scale, was measured by asking participants, how strongly they agreed with statements including 1) "You should know your family history so you can pass it along to your children" and 2) "Traditional celebrations such as baptisms, weddings or graduations add meaning to life," with possible responses ranging from (1) strongly disagree to (5) strongly agree. When a factor analysis was completed, one factor emerged with an Eigenvalue of 3.82. All factors were retained with factor loadings higher than .40 (See Table 1 for scale items and factor loadings). All eight items were summed, creating a new variable that ranged from 8 to 40 , with an $\alpha=.87$. 


\section{Analysis}

After factor analyses were conducted and scales were summed, an OLS regression was performed predicting life satisfaction and resilience at wave three using acculturation and familism, controlling for wave one responses in education, marital status, gender, age and treatment condition. Because the effect of treatment condition was not significant, it was not included in the models for the sake of parsimony.

Table 1 Factor Loadings of 10-item Life Satisfaction Scale and 8-item Familism Scale (N =295)

\section{Life
Satisfaction}

A good spiritual life .69

A positive sense of self (self-esteem)

Leadership abilities and the ability to inspire others

The ability to overcome life's problems

A sense of trust with persons important to you

The ability to overcome disappointments

Social confidence with others

The ability to overcome (conquer) anxiety

Clear life goals and a direction in life

The ability to get enough sleep on a daily basis

You should know your family history so you can pass it along to your children

The good life is lived by staying home and taking care of the family

Children should be taught to be loyal to their family

Traditional celebrations such as baptisms, weddings or graduations add meaning to life

We should preserve our customs and traditions as they contain

Adult children should visit their parents often as an expression

The good life is lived by spending time and bonding with family

It is very important to always to remain close to family even when there is a fight between members of the family 


\section{Results}

The mean life satisfaction score at wave three was 40 with a standard deviation of 6 . 58 , and total resilience score had a mean of 11. 89 with a standard deviation of 2.28. Sixty-four percent of the sample reported being primarily Spanish speaking, 25.08\% reported being bilingual, and $11.07 \%$ reported speaking primarily English. The mean score on the familism scale was 33.87 with a standard deviation of 4.49. For descriptive statistics of all control variables, age, education, marital status and gender, see Table 2.

An OLS regression analysis was then estimated, predicting life satisfaction at wave three, controlling for life satisfaction at wave one, age, gender, education and marital status $\left(\mathrm{F}(8,264)=9.84, \mathrm{p}>.000 ; \mathrm{R}^{2}=.23\right)($ see Table 3$)$. We observed a significant increase of $\beta=2.04(p>.05)$ in general life satisfaction for individuals who were bilingual/ bicultural compared to those who were primarily Spanish speaking/low acculturated. For individuals that primarily spoke English, no significant difference was found. A positive relationship was also found between familism and general life satisfaction $(\beta=.19, p>.05)$. For every one additional point on the familism scale, we expected a .19 increase in general life satisfaction. While this effect size is rather small, it indicates that a connection to tradition may promote general life satisfaction.

Table 2 Means and Standard Deviations for the Analytic Sample

\begin{tabular}{|c|c|c|c|}
\hline & Mean & SD & $\%$ \\
\hline Life satisfaction W1 & 36.65 & 7. 04 & \\
\hline Life satisfaction W3 & 40.00 & 6.58 & \\
\hline Resilience W1 & 10.79 & 2. 61 & \\
\hline Resilience W3 & 11.89 & 2. 28 & \\
\hline Familism & 33.87 & 4. 49 & \\
\hline Age & 38.67 & 6.90 & \\
\hline Education $^{\mathrm{a}}$ & 3.29 & 1.58 & \\
\hline \multicolumn{4}{|l|}{ Acculturation } \\
\hline Primarily Spanish & & & 63.84 \\
\hline Bilingual & & & 25.08 \\
\hline Primarily English & & & 11.07 \\
\hline \multicolumn{4}{|l|}{ Gender } \\
\hline Female & & & 86.81 \\
\hline Male & & & 13.19 \\
\hline \multicolumn{4}{|l|}{ Marital status } \\
\hline Married & & & 60.91 \\
\hline Single & & & 39.09 \\
\hline
\end{tabular}


When the same model was estimated predicting resilience, controlling for resilience at wave one, a very similar pattern was observed $\left(F(8,264)=7.44, p>.000 ; R^{2}=.18\right)$ (see Table 3). For bilingual speakers, a significant increase was predictive of high resilience, with this group scoring on average $.84(\mathrm{p}>.001)$ points higher than their primarily Spanish-speaking counterparts, controlling for wave one, age, gender, education, and marital status. Unlike the previous model, those who primarily spoke English were also predicted to have significantly better scores on the resilience scale $(\beta=.95, p>.05)$ than primarily Spanish speakers. A positive relationship was also found between higher scores on the familism scale and resilience $(\beta=.07, p>.001)$. While the effect size is again not large, a positive relationship beyond levels of acculturation indicates a protective effect of staying connected to a traditional orientation toward family.

Table 3 Regression Predicting Life Satisfaction and Resilience among Latinos Living in the US $(N=273)$

\begin{tabular}{lrlrrr}
\hline & \multicolumn{3}{c}{ Life satisfaction W3 } & \multicolumn{2}{c}{ Resilience W3 } \\
& $\boldsymbol{\beta}(\boldsymbol{S E})$ & Sig & $\boldsymbol{\beta}(\boldsymbol{S E})$ & Sig \\
\hline Life satisfaction W1 & $.34(.06)$ & $* * *$ & & \\
Resilience W1 & & & $.25(.05)$ & $* * *$ \\
Spanish speaking & & & & \\
Bilingual & $2.04(.91)$ & $*$ & $.84(.33)$ & $* *$ \\
English speaking & $2.01(1.29)$ & & $.95(.46)$ & $*$ \\
Familism & $.19(.09)$ & $*$ & $.07(.03)$ & $* *$ \\
Female (1) & $1.23(1.08)$ & & $.40(.39)$ & \\
Education & $.03(.25)$ & & $.03(.09)$ & \\
Married $(1)$ & $1.51(.75)$ & $*$ & $.48(.27)$ & + \\
Age & $.01(.05)$ & & $.01(.02)$ & \\
con & $18.18(3.69)$ & $* * *$ & $5.32(1.31)$ & $* * *$ \\
$\mathrm{R}^{2}$ & 0.23 & $* * *$ & & 0.18 & $* * *$ \\
\hline$* * * \mathrm{p}<.000, * * \mathrm{p}<.01, * \mathrm{p}<.05,+\mathrm{p}<.10$ & & & & \\
\hline
\end{tabular}

\section{Discussion}

Among Latino adults living in the Southwest, the findings lend support to the hypothesis that individuals who have been able to integrate aspects of both the host culture and the culture of origin, or those that are bicultural, have better mental health outcomes than those who are still culturally separate (Berry, 2005). Immigrants who exhibited an integrative reaction had higher ratings of life satisfaction than those individuals that chose to remain culturally separate from the American culture (primarily Spanish speaking). It is important to note that immigrants who had fully assimilated (primarily English speaking) did not show high ratings of life satisfaction. These findings may indicate that retaining aspects of one's culture of origin and embracing elements of the host culture, may promote the best mental health outcomes among Latino immigrants. 
Having the skills to navigate the host culture while remaining grounded in the culture of origin promoted life satisfaction. This was not the case for resilience. Both individuals that reported being culturally integrated (bilingual) and assimilated (primarily English speaking) reported higher rates of resilience than their separated or primarily Spanishspeaking counterparts. The results also lend support to the hypothesis that identification with traditional norms about family would result in higher levels of life satisfaction and resilience, again illustrating the potentially protective effect of remaining connected to traditional norms and values while acquiring skills like language proficiency, which allows an individual to be more successful in navigating American culture.

\section{Limitations}

These results have some geographical, sampling, and other limitations that should be noted. First, although acculturative stress was the assumed pathway between acculturation and life satisfaction, a measure of stress was not included in the survey; therefore, this relationship could not be tested directly. Another limitation is that not all individuals surveyed at pre-test completed a post-test survey, which potentially biased the results. The vast majority of the parents were monolingual in Spanish, or bilingual with a preference to communicate in Spanish. Because this program was developed in a southwestern metropolitan area, it is uncertain how the program would generalize to other Mexican American communities outside the southwestern metropolitan area, particularly where Mexican American parents may be in the minority. In addition, because this particular southwestern area has a distinctive socio-political environment, the program may also be uniquely characteristic of that specific environment. Third, parents self-selected whether they wanted to participate and wanted their child to participate, possibly creating a selection bias. Difference in self-selection by treatment condition could be due to level of interest of parents willing to participate in a youth-only intervention compared to participating in a parent-based intervention or receiving nothing. It should be noted that once baseline data were collected, an unconditional model in Mplus was conducted to examine the interclass correlation (ICC) between schools. The unconditional model indicated non-significant ICCs between schools.

\section{Implications for Social Work Practice}

The findings have implications for both macro and micro social work practice with Latinos, specifically first-generation Mexican migrants. The large and growing number of Mexican immigrants living in the United States, both legally and in the shadows, makes understanding the circumstances that promote optimal physical and mental health among this population, and working to eradicate social and economic barriers to mental health care, crucial concerns in the field of social work. Although the process of immigration and acculturation presents a host of unique risk factors, this study has identified a bicultural orientation and an endorsement of traditional family norms as protective. These findings run counter to the typical American norm that encourages complete assimilation into the dominant American culture. Instead, the findings suggest that policies that aim to separate individuals from their country of origin and fully integrate them into American society (i.e. English only policies) might have a negative impact on well-being. 
Furthermore, the findings suggest that failing to adopt essential skills necessary for integration such as English language proficiency is also related to lower levels of life satisfaction. In fact, individuals who primarily spoke English were found to be more resilient than those who primarily spoke Spanish. These findings might reflect discriminatory systems, but they indicate a need to acquire new skills to successfully navigate American culture (Torres, 2010). However, these skills do not need to be obtained at the expense of an individual's culture of origin. In addition to ending discriminatory policies that create barriers for immigrants, policies need to be created on the national, state, local, and agency level that allow individuals to co-exist in micro and mezzo systems that reflect their culture of origin and the larger systems of work and school, places typically dominated by American norms and values.

When applying traditional psychotherapeutic models with Latinos in direct practice, social workers need to consider the impact of acculturation to ensure that they arrive at an accurate diagnosis and provide effective treatment. This may require culturally adapting existing intervention strategies so they not only better fit the population being served, but also build and strengthen protective cultural norms and values. It is also essential for social workers to identify and address policies that perpetuate social and economic barriers to mental health care. Ultimately, creating spaces that facilitate multicultural identities for Mexican immigrants, in both social work practice as well as the larger society, may be crucial to promoting quality mental health systems for populations that face stressors in the process of acculturation.

This study suggests several possible avenues for future research. Both the acculturation and resilience measures used in this research only scratch the surface of this complex process; therefore, further studies need to focus on what promotes and hinders resilience among new immigrants as they move through the process of acculturation. Additionally, future research should explore how the larger social context may be interacting with culture to hinder or promote well-being. Specifically, more needs to be understood about the immigrants' experiences with discrimination and structural barriers to upward mobility, which may impact the adaptation of a bicultural orientation. Research on the socio, economic, and psychological immigration processes are crucial to providing culturally competent social work services to Latinos in the United States.

\section{References}

Abrams, K. K., Allen, L. R., \& Gray, J. J. (2009). Disordered eating attitudes and behaviors, psychological adjustment, and ethnic identity: A comparison of black and white female college students. International Journal of Eating Disorders, 14(1), 4957.

Ahern, N. R., Kiehl, E. M., Lou Sole, M., \& Byers, J. (2006). A review of instruments measuring resilience. Issues in comprehensive Pediatric nursing, 29(2), 103-125.

Andrews, F. M., \& McKennell, A. C. (1980). Measures of self-reported well-being: Their affective, cognitive, and other components. Social Indicators Research, 8, 127-155. 
Berry, J. W. (1997). Immigration, acculturation and adaptation. Applied Psychology: An International Review, 46(1), 5-68.

Berry, J. W. (2005). Acculturation: Living successfully in two cultures. International Journal of Intercultural Relations, 29(6), 697-712.

Castillo, L. G., Conoley, C. W., \& Brossart, D. F. (2004). Acculturation, white marginalization, and family support as predictors of perceived distress in Mexican American female college students. Journal of Curriculum, 51(2), 151-157.

Castro, F. G., Marsiglia, F. F., Kulis, S., \& Kellison, J. G., (2010). Lifetime segmented assimilation trajectories and health outcomes in Latino and other community residents. American Journal of Public Health, 100(4), 669-676.

Collishaw, S., Pickles, A., Messer, J., Rutter, M., Shearer, C., \& Maughan, B. (2007). Resilience to adult psychopathology following childhood maltreatment: Evidence from a community sample. Child Abuse \& Neglect, 31(3), 211-229.

Cuellar, I., Bastida, E., \& Braccio, S. M. (2004). Residency in the United States, subjective well-being, and depression in an older Mexican-origin sample. Journal of Aging and Health, 16(4), 447-466.

Davydov, D. M., Stewart, R., Ritchie, K., \& Chaudieu, I. (2010). Resilience and mental health. Clinical Psychology Review, 30(5), 479-495.

Diener, E., Napa-Scollon, C. K., Oishi, S., Dzokoto, V., \& Suh, E. M. (2000). Positivity and the construction of life satisfaction judgments: Global happiness is not the sum of its parts. Journal of Happiness Studies, 1(2), 159-176.

Fraser, M., Richman J., \& Galinsky, M. (1999). Risk, protection, and resilience: Toward a conceptual framework for social work practice. Social Work Research, 23(3), 131143.

Gilman, R., Huebner, E. S., \& Laughlin, J. (2000). A first study of the Multidimensional Students' Life Satisfaction Scale with adolescents. Social Indicators Research, 52(2), $135-160$.

Gordon, M. M. (1964). Assimilation in American life: The role of race, religion and national origins. New York, NY: Oxford University Press.

Greene, R., Galambos, C., \& Lee, Y. (2004). Resilience theory. Journal of Human Behavior in the Social Environment, 8(4), 75-91.

Guo, W., \& Tsui, M. (2010). From resilience to resistance: A reconstruction of the strengths perspective in social work practice. International Social Work, 53(2) 233245.

Headey, B., Kelley, J., \& Wearing, A. (1993). Dimensions of mental health: Life satisfaction, positive affect, anxiety and depression. Social Indicators Research, 29(1), 63-82. 
Hérbert, R. (1996). Portraits of resilience: The urban life experience of gifted Latino young men. Roeper Review, 19(2), 82-91.

Holleran, L. K., \& Waller, M. A. (2003). Sources of resilience among Chicano/a youth: Forging identities in the borderlands. Child and Adolescent Social Work Journal, 20(5), 335-350.

Jenson, J. M., \& Fraser, M. W. (2006). A risk and resilience framework for child, youth, and family policy. In J. M. Jenson \& M. W. Fraser (Eds.), Social policy for children $\&$ families: A risk and resilience perspective (pp. 1-18). Thousand Oaks, CA: Sage.

Karan, O. C., Lambour, G., \& Greenspan, S. (1990). Persons in transition. In R. L., Schalock, \& M. J. Begab, (Eds.), Quality of Life: Perspectives and Issues (pp. 85-92). Washington, DC: American Association on Mental Retardation.

Kelly, M. C. (1971). Las fiestas como reflejo del orden social: El caso de San Xavier del Bac. America Indigena, 31(1), 141-161.

Konerua, V., Weisman de Mamania, A., Betancourt, H., \& Flynn, P. (2007). Acculturation and mental health: Current findings and recommendations for future research. Applied and Preventative Psychology, 12, 76-96.

LaFromboise, T., Coleman, H. L. K., \& Gerton, J. (1993). Psychological impact of Biculturalism: Evidence and theory, Psychological Bulletin. 114(3) 395-412.

Lara, M., Gamboa, C., Kahramanian, M. I., Morales, L. S., \& Hayes Bautista, D. E. (2005). Acculturation and Latino health in the United States: A review of the literature and its sociopolitical context. Annual Review of Public Health, 26, 367-397.

Lechuga, J. (2008). Is acculturation a dynamic construct? Hispanic Journal of Behavioral Sciences, 30(3), 324-339.

Lueck, K., \& Wilson, M. (2011). Acculturative stress in Latino immigrants: The impact of social, socio-psychological and migration-related factors. International Journal of Intercultural Relations, 35(2), 186-195.

Martín, G., \& Martín, B. V. (1991). Research with Hispanic populations. Newbury Park, CA: Sage.

Marsiglia, F. F., \& Hecht, M. L. (2005). Keepin' it REAL: An evidence-based program. Santa Cruz, CA: ETR Associates.

Masten, A. S. (2001). Ordinary magic: Resilience processes in development. American psychologist, 56(3), 227-238.

Melville, M. B. (1978). Mexican women adapt to migration. International Migration Review, 12(2), 225-235.

Miranda, A. O., Estrada, D., \& Firpo-Jimenez, M. (2000). Differences in family cohesion, adaptability, and environment among Latino families in dissimilar stages of acculturation. The Family Journal, 8(4), 341-350. 
Miranda, A. O., \& Umhoefer, D. L. (1998). Depression and social interest differences between Latinos in dissimilar acculturation stages. Journal of Mental Health Counseling, 20(2), 159-171.

Myers, D. G., \& Diener, E. (1995). Who is happy? Psychological Science, 6(1), 10-19.

Nguyen, L., \& Peterson, C. (1993). Depressive symptoms among Vietnamese-American college students. The Journal of Social Psychology, 133(1), 65-71.

Ong, A. D., Bergeman, C., Bisconti, T. L., \& Wallace, K. A. (2006). Psychological resilience, positive emotions, and successful adaptation to stress in later life. Journal of Personality and Social Psychology, 91(4), 730-749.

Ortiz, V., \& Arce, C. (1984). Language orientation and mental health status among persons of Mexican descent. Hispanic Journal of Behavioral Science, 6(2), 127-143.

Pavot, W., \& Diener, E. (2008). The satisfaction with life scale and the emerging construct of life satisfaction. The Journal of Positive Psychology, 3(2), 137-152.

Redfield, R., Linton, R., \& Herskovits, M. J. (1936). Memorandum for the study of acculturation. American Anthropologist, 38(1), 149-152.

Rodriguez, N., Mira, C. B., Paez, N. D., \& Myers, H. F. (2007). Exploring the complexities of familism and acculturation: Central constructs for people of Mexican origin. American Journal of Community Psychology, 39(1-2), 61-77.

Rogler, L. H. (1989). The meaning of culturally sensitive research in mental health. The American Journal of Psychiatry, 146(3), 296-303.

Saenz, R. (2010). Latinos in America 2010. Population Bulletin Update. Retrieved from http://www.prb.org/pdf10/latinos-update2010.pdf

Salgado de Snyder, V. N. S. (1987). Factors associated with acculturative stress and depressive symptomatology among married Mexican immigrant women. Psychology of Women Quarterly, 11(4), 475-488.

Shen, B. J., \& Takeuchi, D. T. (2001). A structural model of acculturation and mental health status among Chinese Americans. American Journal of Community Psychology, 29(3), 387-418.

Schinke, S., Brounstein, P., \& Gardner, S. (2002). Science-based prevention programs and principles, 2002 (Publication Number (SMA) 03-3764). Rockville, MD: Center for Substance Abuse Prevention, Substance Abuse and Mental Health Services Administration.

Stonequist, E. V. (1935). The problem of the marginal man. American Journal of Sociology, 41(1), 1-12.

Suldo, S. M., \& Huebner, E. S. (2004). Does life satisfaction moderate the effects of stressful life events on psychopathological behavior during adolescence? School Psychology Quarterly, 19(2), 93-105. 
Tugade, M. M., \& Fredrickson, B. L. (2004). Resilient individuals use positive emotions to bounce back from negative emotional experiences. Journal of Personality and Social Psychology, 86(2), 320-333.

Torres, L. (2010). Predicting levels of Latino depression: Acculturation, acculturative stress, and coping. Cultural Diversity and Ethnic Minority Psychology, 16(2), 256263.

Unger, J., Ritt-Olson, A., Wagner, K., Baezconde-Garbanati, L., \& Soto, D. (2007). Comparison of acculturation measures among Hispanic/Latino adolescents. Journal of Youth and Adolescents, 36(4), 555-565.

U. S. Census Bureau. (2012). American Fact Finder: Profile of General Population and Housing Characteristics: 2010. Retrieved from http://factfinder2.census.gov/faces/tableservices/jsf/pages/productview.xhtml?pid=D EC 10 DP DPDP1\&prodType $=$ table

U. S. Department of Health and Human Services. (2001). Mental Health: Culture, Race, and Ethnicity - A Supplement to Mental Health: A Report of the Surgeon General. Rockville, MD: USDHHS, Substance Abuse and Mental Health Services Administration, Center for Mental Health Services.

U. S. Department of Health and Human Services. (2012). Office of Disease Prevention and Health Promotion. Healthy People 2020. Washington, DC. Retrieved from http://www.healthypeople.gov/2020

Usborne, E., \& Taylor, D. M. (2010). The role of cultural identity clarity for self-concept clarity, self-esteem, and subjective well-being. Personality and Social Psychology Bulletin, 36(7), 883-897.

\section{Author note:}

Address correspondence to: Flavio F. Marsiglia, Ph. D., School of Social Work, Arizona State University, 411 N. Central Avenue, Suite 720, Phoenix, AZ 85004. Email: marsiglia@asu.edu 